\title{
O impacto da COVID-19 em educação pré-escolar: análise das estratégias desenvolvidas
}

\author{
Cristiana Ribeiro ${ }^{a}$, Ana Claudia Loureiro ${ }^{a}$, Cristina Mesquita ${ }^{a}$, Rui Lopes ${ }^{b}$ \\ ${ }^{\mathrm{a} C}$ Centro de Investigação em Educação Básica, Instituto Politécnico de Bragança, Portugal, ${ }^{\mathrm{b}}$ Centro de \\ Investigação em Digitalização e Robótica Inteligente, Instituto Politécnico de Bragança, Portugal
}

\begin{abstract}
Resumo
A situação pandémica provocada pela COVID-19 tem vindo a promover a necessidade de um reajustamento social, alterando muitas das dinâmicas em muitos setores de atividade. A necessidade de controlar o avanço $e$ disseminação do contágio levou as autoridades de saúde a desaconselhar encontros e sessões presenciais. As escolas tiveram que se readaptar tendo em conta a necessidade de garantir a aprendizagem das crianças e jovens. Esta readaptação conduziu a formas de contacto não presencial, utilizando dispositivos tecnológicos que potenciam o ensino à distância. O recurso a estes dispositivos requer um mínimo de competências tecnológicas e digitais e uma adequação dos processos de educação e ensino, muito centrados na autonomia e autoaprendizagem das crianças e dos jovens. Contudo, nos contextos educativos onde os processos de ensino-aprendizagem são mais focados no educador elou professor, as tecnologias tendem a ser menos valorizadas e, quando usadas, geralmente traduzem-se em sessões puramente tecnicistas. Atendendo à diversidade de realidades que as instituições de educação pré-escolar apresentam, este estudo visa saber como é que os educadores de infância experimentaram profissionalmente o período de confinamento físico e quais as estratégias que as instituições usaram para colmatar as dificuldades provocadas pela situação pandémica. Mais especificamente, pretendemos saber como é que os educadores de infância estabeleceram interações à distância com as crianças, de forma a promover a sua aprendizagem. Trata-se de uma investigação que recorreu ao questionário como instrumento de recolha de dados, do qual se obtiveram 502 respostas. Procedeu-se, posteriormente, à análise estatística descritiva, na análise das questões de escolha múltipla e análise de conteúdo para a interpretação das respostas abertas. Deste estudo, salienta-se o esforço que os educadores tiveram para manterem o contacto com o grupo de crianças e com as famílias, recorrendo, mesmo, ao Correio Postal (CTT) para o efeito.
\end{abstract}


Palavras-chave: Tecnologias digitais, conceções docentes, ensino à distância.

\section{O uso das tecnologías pelos docentes}

Existe já um conjunto de estudos que investigam o uso das tecnologias por parte de agentes educativos. Parte deles analisa as práticas educativas de educadores de infância e professores dos diferentes níveis de ensino, verificando se estes utilizam as tecnologias, de que forma o fazem e quais as suas dificuldades, cruzando os dados com as suas conceções. Alguns apontam que, ainda que as crianças despertem interesse pelas tecnologias, o seu uso é reduzido em sala de aula pelos educadores e professores (Iacob, 2016). Por outro lado, alguns estudos revelam que os professores usam as tecnologias e reconhecem a sua importância (Brito, 2010; Gorder, 2008; Folho, Santos \& Abar, 2017; Rub, 2015), mas, após a análise das suas práticas educativas, deparamo-nos com um uso meramente tradicionalista, transmissivo, não reflexivo e não crítico (Folho, Santos, \& Abar, 2017; Gorder, 2008; Oliveira \& Dias, 2014).

Em contraponto, há vários estudos que revelam a falta de formação docente como um dos grandes problemas no uso pedagógico das tecnologias, indicando que a maioria dos professores e educadores o fazem por autoconhecimento, autodescoberta e autoformação (Brito, 2010; Laranjeiro, Antunes, \& Santos, 2017). Santos, Castelano e Almeida (2012) vão mais longe apontando dados que demonstram que, mesmo quando as escolas oferecem cursos de formação docente, estes não despertam muito interesse em os fazer, chegando mesmo a desistir. Outra contribuição apontada por esses investigadores é o facto de que muitos docentes apresentam dificuldades em utilizar didática e efetivamente as tecnologias em suas práticas educativas, mesmo após participar de formações.

No que se refere aos recursos tecnológicos que os professores utilizam, os dados variam de pesquisa para pesquisa. Folho, Santos e Abar (2017) descobriram que as TIC eram usadas apenas como um recurso adicional, para a consulta de revistas, jornais e livros digitais, envio de mensagens por correio eletrónico, busca na internet, apresentação de filmes e consulta de blogs. Rub (2015), numa investigação com educadores e professores do 1. ${ }^{\circ}$ ciclo do ensino básico, obteve dados em que os investigados usavam as tecnologias somente como ferramentas de trabalho para criar apresentações, testes e exames de avaliação. As conceções que os professores têm sobre o seu papel em sala de aula influenciam e chegam mesmo a definir o uso que esses fazem das tecnologias em contexto educativo. Como comprovaram Palak e Walls (2009), professores que utilizam metodologias de ensino centradas no modelo transmissivo, tradicionalista e expositivo de conteúdo, não valorizam tanto as tecnologias e não lhes encontram reais vantagens de ensino. Contrariamente, nos estudos realizados por Bergmann e Sams (2017) e Bacich e Moran (2018) evidencia-se que os professores que utilizam metodologias didático- 
pedagógicas mais ativas, percebem o potencial que as TIC têm para o processo de aprendizagem da criança/aluno. Torna-se importante salientar que o uso das tecnologias como meio educativo propõem um repensar sobre a função da escola, do papel do professor e do aluno que se pretende formar.

Segundo Meirinhos e Osório (2015) é necessário transformar a escola de modo a atender às exigências da sociedade do conhecimento tanto quanto é necessário repensar a formação de educadores/professores, tornando-os profissionais atualizados e preparados para propor inovações educativas. De acordo com essa conceção, Loureiro, Cavalcanti e Tavares (2019), revelam que modelos de formação docente pautados em metodologias ativas "é um caminho eficaz para possibilitar que vivenciem experiências de aprendizagem que depois poderão ser transpostas para os contextos onde atuam como educadores" (p. 471). As autoras sugerem que a prática de permitir que os docentes vivenciem momentos de ação e reflexão, durante a formação inicial e/ou contínua, viabiliza a formação do profissional reflexivo, que se revela mais disponível para desenvolver metodologias ativas nos contextos educacionais onde atuam. Ainda segundo Meirinhos e Osório (2015), o uso limitado das TIC em contexto escolar, por parte dos educadores/professores, enfraquece a utilização de formas alternativas nas práticas de modo a resultarem melhorias significativas na aprendizagem das crianças/alunos. Assim, incorporar novas tecnologias, sem as aliar a modelos participativos, não resultarão em melhorias educacionais (Meirinhos \& Osório, 2015). A criação de ambientes favorecedores de aprendizagem, onde as crianças/alunos participem e sejam construtores ativos na aprendizagem, implica a recriação da pedagogia fundada na ética do respeito, que promove a autonomia da pessoa em formação (Lopes, Mesquita, Durán-Sánchez, \& Coca, 2020).

Esta perspectiva inspirou o presente estudo, que se centra no âmbito da educação préescolar e que, considerando este momento particular, provocado pela COVID-19, teve como objetivos investigar (i) quais as estratégias adotadas pela instituição para garantir a ação com as crianças; (ii) quais os recursos utilizados para manter o contato com as crianças; (iii) a quem pertencem os recursos utilizados; (iv) quais foram as práticas educativas dos educadores de infância durante a quarentena.

\section{Metodologia}

Este estudo decorreu durante a fase de pandemia provocada pelo Coronavírus que afetou, de forma inusitada e nunca antes vivenciada, muitos países, incluindo Portugal. As escolas e os jardins de infância viram-se obrigados a fechar e repensar as suas práticas educativas. Neste estudo, foi nosso intuito investigar qual foi o trabalho realizado pelos educadores de infância portugueses, com as crianças e as suas famílias, durante os mais de 60 dias de quarentena que ficaram afastados do contexto educativo. 
Este estudo segue uma linha metodológica interpretativa e utilizou o questionário como técnica de recolha de dados. Para a interpretação e discussão dos dados utiliza-se uma análise estatística descritiva, para o conjunto das questões fechadas, e uma análise interpretativa, tipo análise de conteúdo, para as questões abertas (Aires, 2015; Morais \& Neves, 2007). O questionário era constituído por 15 perguntas: seis delas de resposta aberta e nove de resposta fechada, organizadas em três blocos: (I) Identificação do participante; (II) Ação educativa na quarentena; e (III) Dificuldades sentidas no decurso da pandemia a nível profissional. Neste estudo, iremos focar-nos apenas nos blocos I e II que respondem aos objetivos traçados. Os restantes dados serão analisados na continuidade desta investigação, num estudo mais alargado e aprofundado.

O formulário foi validado por um público que apresenta o mesmo perfil do universo de atores pesquisados e foram efetuados os ajustes necessários. O questionário foi, posteriormente, disponibilizado na aplicação Google Formulários e distribuído via online através da reconhecida Associação de Profissionais de Educação de Infância em Portugal (APEI) e de algumas redes sociais. No total obtiveram-se 502 respostas de educadores de infância das diferentes partes de Portugal.

\section{Análise e discussão dos resultados}

Valer-se do uso de questionário e envio por meios eletrónicos e redes socias, como canal de comunicação e pesquisa com o público alvo, tem a vantagem de atingir a um maior número de participantes, mas não significa ter maior número de devolutivas (Galan \& Vernette, 2000). Neste estudo, tivemos um retorno de 502 educadores(as) de infância no ativo.

Das respostas obtidas no bloco I "Identificação", tínhamos como objetivo conhecer os participantes. Apercebemo-nos de uma enorme predominância do sexo feminino 99\% (497 participantes), comparativamente com $1 \%$ do sexo masculino (5 participantes). Dos participantes 33,5\% têm idades compreendidas entre 51 e 60 anos, seguidos de 29,3\%, com idade entre 41 e 50 anos; $23,9 \%$ entre 31 e 40 anos, $8 \%$ entre 20 a 30 anos e, por último, pessoas com mais de 60 anos corresponde a $5,4 \%$.

Muitas educadoras de infância $(58,4 \%)$ são licenciadas. Entre os demais apresentam-se profissionais com mestrado $(25,1 \%)$, pós-graduação $(7,6 \%)$, especialização $(4,4 \%)$, bacharelato $(3,6 \%)$ e doutoramento $(1 \%)$. O tempo de serviço varia entre 11 e 20 anos (27,1\%), 21 e $30 \operatorname{anos}(25,9 \%), 31$ e $40 \operatorname{anos}(25,5 \%), 0$ e $10 \operatorname{anos}(19,1 \%)$ e mais de 40 anos $(2,4 \%)$. Trabalham maioritariamente numa instituição pública $(44,4 \%)$. Relativamente às idades das crianças com que atuam, estas são maioritariamente grupos mistos de crianças com 3,4 e 5 anos de idade $(51,4 \%)$.

Com os dados obtidos no bloco II "Ação educativa na quarentena”, tínhamos como intuito obter resposta aos objetivos definidos nesta investigação. A primeira questão pretende 
recolher informação sobre as estratégias adotadas pelas instituições, onde trabalham os profissionais participantes neste estudo, para estes manterem a ação com as crianças.

As respostas evidenciam diferentes categorias e níveis de complexidade. Se algumas orientações são mais simplificadas, por exemplo com respostas de estratégias como "educação à distância" ou "teletrabalho", de forma a "manter o contacto com as famílias", outras envolvem mais detalhe e, por isso, foram criadas as seguintes categorias: recursos; prática educativa; retorno da ação; tempo/frequência; apoio institucional.

No que se refere aos recursos, algumas instituições deram indicação ou sugestão sobre os recursos digitais e/ou analógicos que os profissionais deveriam utilizar para estabelecer comunicação com os encarregados de educação e as crianças, evidente nas respostas "Salas online, Videoconferência através de salas criadas no moodle do Agrupamento, contactos telefónicos", "Contato telefónico e por email", "Criação de um e-mail para cada criança e a utilização da plataforma Google Classroom”. Através da resposta exemplo "Os contactos foram realizados por mail, WhatsApp, MSN, telefone e via CTT, para as famílias que não tinham meios digitais", observamos que algumas instituições delinearam estratégias de ação para as crianças que não tinham acesso a recursos digitais. As respostas vão ao encontro dos recursos mencionados nas respostas evidenciadas na figura 1.

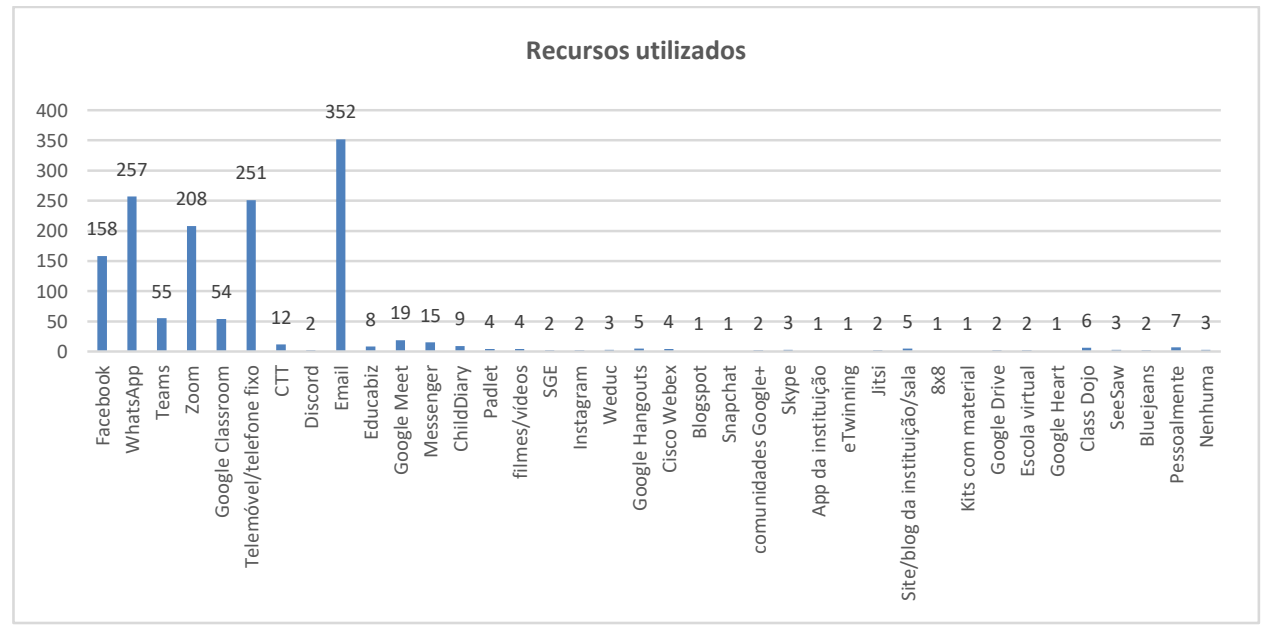

Fig. 1 Recursos utilizados

Fonte: Gráfico extraido do bloco (II) referente à questão 2 do questionário feito na plataforma Google Formulários

Relativamente à prática educativa, alguns profissionais receberam indicações do tipo de trabalho que deveriam realizar, indo desde o "envio de atividades semanais" até a indicações mais complexas, como podemos observar na afirmação: "partilha de vivências espontâneas pelas famílias, com feedback positivo da parte dos adultos responsáveis do grupo; envio de sugestões de atividades diárias (plano semanal) com temas que sabia serem 
do interesse do grupo, questionando sempre as famílias sobre os seus interesses durante a quarentena para ajustar as propostas; Uma videochamada por semana (apesar da pouca adesão); e valorização das participações no momento exato das partilhas para garantir que as crianças não ficavam sem resposta às suas participações”. A maioria das respostas evidencia que a estratégia mais adotada era o envio de planificações semanais aos encarregados de educação que posteriormente as desenvolviam com as crianças: criar contacto com os EE [Encarregados de Educação] e enviar planificações com atividades que os pais pudessem fazer em casa com as crianças"; "envio mensal de atividades diversificadas e possíveis de realizar em casa com ajuda dos pais".

Uma outra categoria observada, ainda que em pouca quantidade, refere-se ao retorno da ação. Nas respostas "semanalmente era elaborado um plano de atividade direcionado à criança, colocado na plataforma e o retorno era feito pela mesma plataforma"; "contatos com os Encarregados de Educação, elaboração de planos semanais com muito feedback dos trabalhos realizados pelas crianças" e "devolução das atividades por parte dos Enc. Educação através de fotos e de vídeos" observamos que, em alguns casos, o feedback foi planeado, chegando a haver indicações da plataforma a utilizar para tal.

Relativamente à categoria tempo/frequência, em algumas situações, existiram indicações claras da frequência com que os profissionais deveriam manter o contacto com as crianças, como evidenciam algumas respostas indicadas anteriormente.

Por último, apresenta-se a categoria apoio institucional. Esta categoria divide-se em duas subcategorias diferentes: o apoio às crianças e o apoio aos profissionais. $\mathrm{O}$ apoio dado às crianças foca-se essencialmente na cedência de materiais "distribuição de Kits às crianças sem recursos informáticos”, mas existe uma resposta que salienta um dado importante, o apoio alimentar: "acompanhamento através de recursos digitais e contactos telefónicos. Em alguns casos apoio alimentar". Já o apoio dados aos profissionais foi em termos de recursos "Disponibilizaram-se as ferramentas que precisássemos e que havia na escola".

Das respostas obtidas recolhemos dados que evidenciam que 15 profissionais não tiveram qualquer orientação por parte das instituições onde trabalhavam, como se confirma nas respostas "nenhuma" e "as estratégias adotadas foram nulas, as que existiram foram exclusivamente por iniciativa pessoal. Não existiram nem estratégias nem orientações”. Os dados demonstram ter sido "decretado lay-off" por quatro instituições, pelo que, ficava ao critério de cada educador(a) de infância o contacto ou não com as crianças.

Com a segunda questão do bloco II quisemos perceber quais foram as plataformas ou recursos digitais (ou outros) que os educadores de infância usaram durante o período de quarentena para estabelecer contacto com as crianças e com as suas famílias. A figura 1 apresenta o uso do e-mail como o recurso mais usado (352 utilizadores) para comunicar com os encarregados de educação das crianças, seguido do WhatsApp (257 utilizadores), do Zoom (208 utilizadores) e do Facebook (158 utilizadores). A maior parte dos participantes utilizou mais do que um recurso. 
Denotamos um esforço dos participantes para poderem estabelecer contacto com todas as crianças, seja por meios digitais ou não, como o uso do correio postal (CTT) (12 utilizadores) e de contacto pessoal (8 utilizadores) para a entrega de materiais ou propostas de trabalho, como kits com materiais escolares ou pedagógicos, entregues por uma funcionária da instituição na morada da criança ou em encontros semanais com os encarregados de educação e uma ou outra criança.

Prosseguindo, a análise, e ainda dentro do mesmo bloco, a terceira questão teve como objetivo perceber a quem pertenciam os recursos usados e se houve alguma instituição a contribuir com recursos digitais (figura 2).

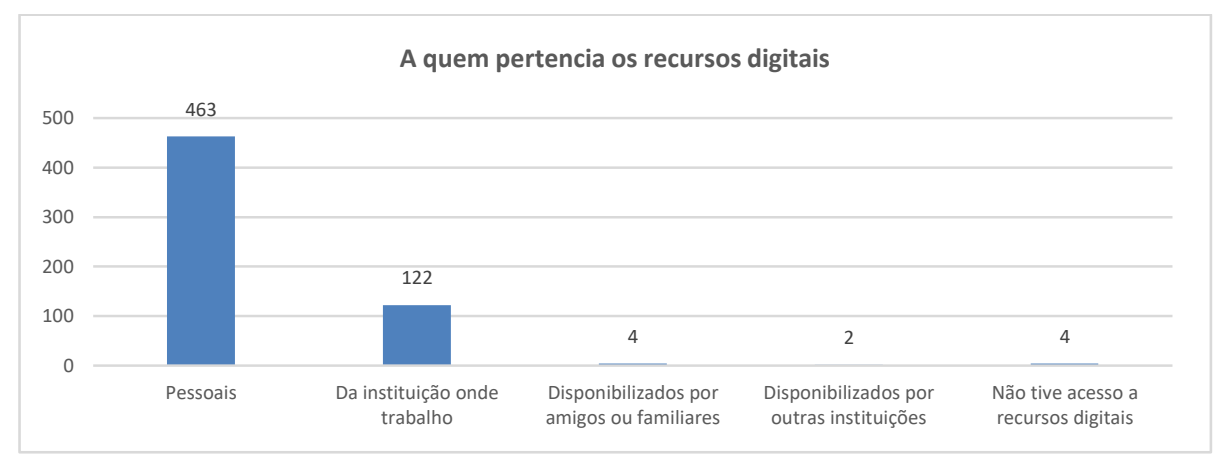

Fig. 2 A quem pertencia os recursos digitais

Fonte: Gráfico extraído do bloco (II) referente à questão 3 do questionário feito na plataforma Google Formulários

No gráfico fica demonstrado que a grande maioria dos(as) educadores(as) de infância utilizou recursos pessoais (463), mas observamos o contribuito de algumas instituições na disponibilização de recursos aos educadores(as) de infância (122), o que vem refutar o salientado na questão referente às estratégias institucionais. Somente quatro educadores de infância relataram não terem tido acesso a nenhum recurso digital. Pelo número de respostas observamos que existiram pessoas a utilizar equipamentos pertencentes a diferentes pessoas.

A última questão em análise teve como objetivo perceber quais foram as práticas educativas dos educadores de infância, assim como perceber quais foram as estratégias adotadas para proporcionar às crianças experiências de aprendizagem (figura 3). 


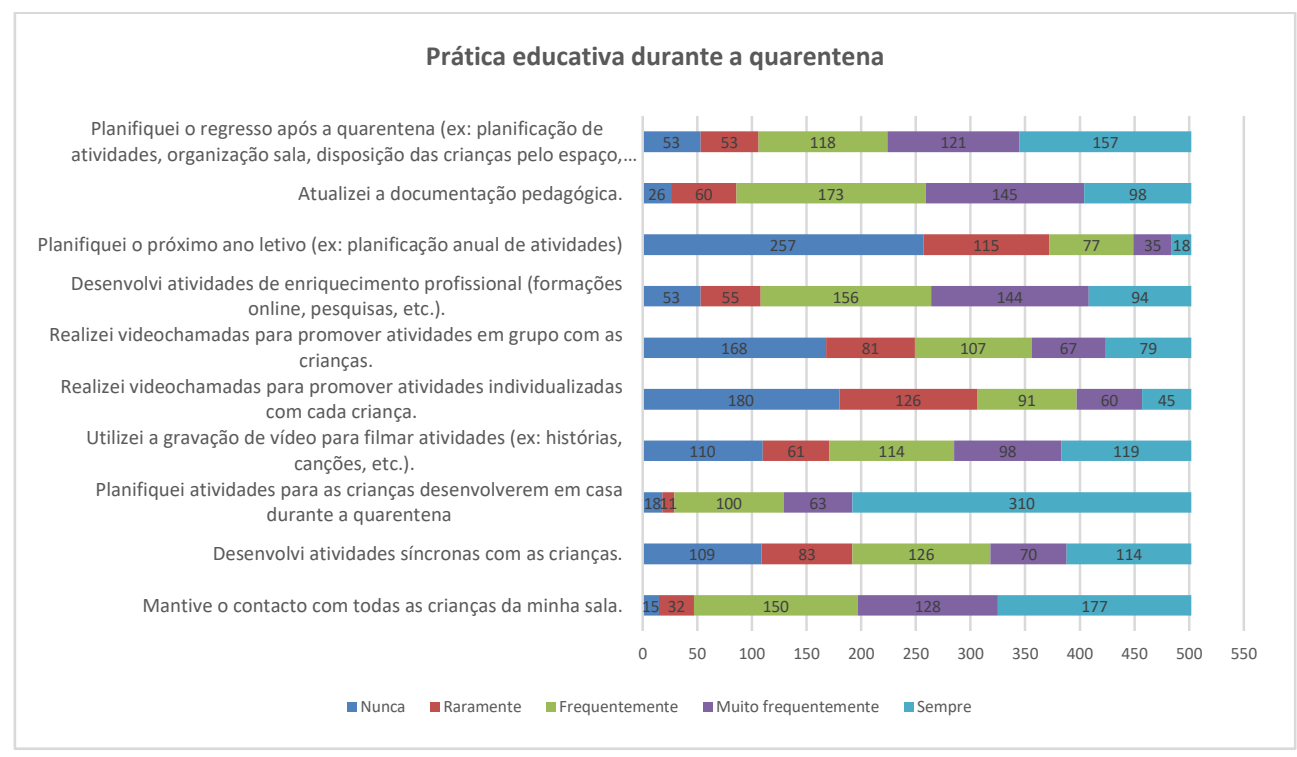

Fig. 3 Práticas educativas durante a quarentena

Fonte: Gráfico extraido do bloco (II) referente à questão 3 do questionário feito na plataforma Google Formulários

Pela leitura do gráfico pode-se observar que nem todos os inquiridos tiveram contacto com todas as crianças da sua sala, observando-se o relato de 15 educadores de infância que nunca tiveram contacto com as crianças, coincidindo com o número de profissionais que não receberam quaisquer indicações/orientações da instituição (figura 3).

Durante a quarentena, as atividades assíncronas prevaleceram em relação às síncronas, ou seja, a planificação de atividades para serem desenvolvidas pelas crianças foram mais utilizadas, 310 participantes referem ter realizado sempre atividades assíncronas, e 114 referem ter realizado sempre atividades síncronas. Neste sentido, as experiências de aprendizagem, ainda que pensadas pelos(as) educadores(as) de infância, foram maioritariamente colocadas em prática pelas crianças com a ajuda dos pais ou encarregados de educação. No que se refere ao envio de atividades planificadas e implementadas pelos profissionais, a gravação de vídeo foi mais utilizada do que a videochamada (tanto para contactar individualmente com as crianças como em grupo).

Os educadores(as) de infância também aproveitaram o período de quarentena para se enriquecerem profissionalmente, para planificarem o regresso após a quarentena, para planificarem o próximo ano letivo e para atualizarem a documentação pedagógica. 


\section{Conclusão}

Esta investigação estuda as práticas educativas dos(as) educadores(as) de infância em período de quarentena, durante o encerramento dos jardins de infância e o cancelamento das atividades presenciais, devido à COVID-19. O tema foi selecionado segundo a pertinência e atualidade, uma vez que quando foram recolhidos os dados os(as) educadores(as) de infância tinham regressado ao trabalho presencial há cerca de duas semanas. Para tal, foi nosso intuito contribuir para um enriquecimento da temática.

O estudo foi realizado através de um questionário online divulgado em Portugal (incluindo as regiões autónomas da Madeira e dos Açores) e respondido por 502 pessoas, maioritariamente mulheres, o que era esperado, uma vez que a profissão docente é maioritariamente feminina. Observamos uma maior percentagem de respostas de educadores(as) com mais de 40 anos de idade, o que vem comprovar que o corpo docente (principalmente do ensino público) em Portugal está envelhecido (OCDE, 2019). Pelas respostas recolhidas podemos referir que poucas foram as instituições que não deram recomendações para um trabalho remoto, tendo algumas aberto "lay-off" e ficando ao critério de cada profissional se mantinha ou não contacto com as crianças. Da grande maioria que recebeu recomendações, uns mencionam umas recomendações menos detalhadas, como por exemplo o trabalho a partir de casa e o não contacto presencial, mas outras vão mais longe mencionando as plataformas que devem usar, o tipo de trabalho que devem fazer e a frequência com que devem contactar com as crianças.

Denota-se um esforço de alguns profissionais em manter o contacto com as crianças, existindo somente quinze profissionais que não estabeleceram qualquer contacto. Houve quem realizasse verdadeiros esforços, recorrendo ao uso dos CTT ou mesmo ao contacto pessoal com as famílias, para poder enviar propostas de trabalho e/ou materiais pedagógicos. As práticas alteraram-se, existindo maior frequência de atividades assíncronas, mas também de trabalho burocrático.

Ainda que da investigação teórica depreendemos que, embora as tecnologias façam parte do interesse das crianças, existem ainda poucos educadores de infância que as utilizam em contexto educativo e, quando o fazem, é essencialmente para uso transmissivo. Esta investigação demonstrou-nos que, se estes profissionais tinham dificuldades no uso das tecnologias e dos recursos digitais, realizaram um grande esforço para as ultrapassar e, em muitos casos, chegaram a experienciar diversas plataformas e recursos.

\section{Referências}

Aires, L. (2015). Paradigma qualitativo e práticas de investigação educacional. Lisboa: Universidade Aberta. 
Bacich, L., \& Moran, J. (org.) (2018). Metodologias ativas para uma educação inovadora: Uma abordagem teórico-prática. Porto Alegre: Penso.

Bergmann, J., \& Sams, A. (2017). Sala de aula invertida: uma metodologia ativa de aprendizagem. Rio de Janeiro: LTC.

Brito, R. (2010). As TIC no jardim-de-infância: Práticas de educadores de infância e crianças portuguesas. In Rocha et al. (Eds.), Atas da CISTI 2010, 5. ${ }^{a}$ Conferência Ibérica de Sistemas e Tecnologias de Informação (pp. 264-268). Santiago de Compostela: AISTI, Universidad de Santiago de Compostela.

Folho, V, Santos, G., \& Abar, C. (2017). Tecnologias da informação e comunicação aplicadas aos processos de ensino e de aprendizagem: Percepção de um grupo focal de professores de uma escola do Maranhão. , 5(2), 3-15.

Galan, J., \& Vernette, E. (2000). Vers une 4éme géneration: Les études de marché. Décisions Marketing, (19), 39-52. Disponível em: www.jstor.org/stable/40592712

Gordor, L. M. (2008). A study of teacher perceptions of instructional technology integration in the classroom. The Delta Pi Epsilon Journal, L(2), 63-76. Disponível em: http://www.dpc.org

Iacob, I. (2016). Perceções das crianças sobre as novas tecnologias na aprendizagem. Lisboa: Instituto Universitário de Lisboa.

Laranjeiro, D., Antunes, M., \& Santos, P. (2017). As tecnologias digitais na aprendizagem das crianças e no envolvimento parental no jardim de infância: Estudo exploratório das necessidades das educadoras de infância. $\quad, \quad 30(2), \quad 223-248$. doi:10.21814/rpe.9367

Lopes, R. P., Mesquita, C., Durán-Sánchez, A., \& Coca, J. R. (2020). The ethical assumptions in higher education. In V. Ratten (Ed.), Technological Progress, Inequality and Entrepreneurship (pp. 87-105). Springer International Publishing. https://doi.org/10.1007/978-3-030-26245-7_6

Loureiro, A., Cavalcanti, C., \& Tavares, C. (2019). Concepções docentes sobre o uso das tecnologias na educação. Renote. Revista Novas Tecnologias na Educação, 17, 468-477. doi: http://dx.doi.org/10.22456/1679-1916.99530.

Meirinhos, M., \& Osório, A. J. (2015). Práticas educativas com TIC: Uma proposta de ação. Revista de Estudios e Investigación en Psicologia y Educación, Extr(13). Acedido em 02/12/2018. Disponível em: http://revistas.udc.es/index.php/reipe/article/view/reipe.2015.0.13.452/pdf_380

Morais, A., \& Neves, I. (2007). Fazer investigação usando uma abordagem metodológica mista. Revista Portuguesa de Educação, 20(2), 75-104.

Moran, J. (2015). Mudando a educação com metodologias ativas. In C. A. Souza \& O. E. T. Morales (Orgs.), Convergências midiáticas, educação e cidadania: Aproximações jovens (pp. 15-33). Ponta Grossa: UEPG/PROEX.

OECD (2019). Education at a Glance 2019: OECD Indicators. Paris: OECD Publishing. https://doi.org/10.1787/f8d7880d-en. 
Oliveira, A., \& Dias, R. (2014). Entre a tentação e a educação: Crescendo com os mundos virtuais. Biosofia, 5, 4-9.

Palak, D., \& Walls, R. T. (2009). Teachers' beliefs and technology practices: A mixed-methods approach. Journal of Research on Technology in Education, 41(4), 417-441.

Rub, M. (2015). Teachers' beliefs and technology use in kindergarten and elementary classrooms. World Journal on Educational Technology, 7(3), 149-156. doi: http://dx.doi.org/10.18844/wjet.v7i3.202

Santo, J., Castelano, K., \& Almeida, J. (2012). Uso de tecnologias na prática docente: Um estudo de caso no contexto de uma escola pública do interior do Rio de Janeiro. In J. F. Matos, N. Pedro, A. Pedro, P. Patrício, J. Piedade, \& S. Lemos (Eds.),

(pp. 1023-1031). Lisboa: IE, Universidade de Lisboa. 